\title{
Sodium butyrate induces apoptosis and accumulation of ubiquitinated proteins in human breast carcinoma cells
}

\author{
Viatcheslav A. Soldatenkov ${ }^{1,2}$, Sarada Prasad", \\ Yaroslav Voloshin ${ }^{1}$ and Anatoly Dritschilo ${ }^{1}$ \\ 1 Department of Radiation Medicine, Division of Radiation Research, \\ Georgetown University Medical Center, Washington DC 20007, USA \\ ${ }^{2}$ corresponding author: Viatcheslav A. Soldatenkov, Department of Radiation \\ Medicine, Georgetown University Medical Center, The Research Bld., Room \\ E-207A, 3970 Reservoir Road, Washington, D.C. 20007-2197, USA \\ tel: (202) 687-1170; fax: (202) 687-2221; \\ e-mail: soldates@gunet.georgetown.edu
}

Received 10.9.97; revised 7.10.97; accepted 24.10.97

Edited by J. Cidlowski

\begin{abstract}
To investigate the possible relationship between apoptosis and the ubiquitin pathway we examined the patterns of ubiquitinated proteins in the human breast carcinoma MCF-7 cell line following induction of apoptotic death by sodium butyrate. Apoptosis in these cells was associated with internucleosomal DNA fragmentation and proteolytic cleavage of poly(ADP-ribose) polymerase. By dual in situ antiubiquitin immunofluorescence and chromatin DNA staining, we demonstrated that ubiquitin fluorescence was increased specifically in cells that underwent sodium butyrate-mediated apoptosis. The extent of ubiquitin incorporation into protein conjugates was examined in both adherent (not yet apoptotic) and floating (apoptotic) cell populations. We found that apoptotic cells exhibited enhanced intensity of ubiquitin-immunoreactive conjugates, whereas adherent cells did not. In addition, two-dimensional immunoblot analysis of proteins from apoptotic cells identified a set of isomeric ubiquitinated conjugates located at a pl range of 4.24.6 and a $\mathrm{M}_{\mathrm{r}}$ approximately of $30 \mathrm{kDa}$. These data indicate that the ubiquitin pathway may play a role in the sodium butyrateinduced apoptotic program in breast carcinoma cells.
\end{abstract}

Keywords: apoptosis; sodium butyrate; ubiquitin; breast carcinoma

Abbreviations: DAPI, 4' ,6'-diamidino-2-phenylindole; calceinAM, calcein acetoxymethyl ester; PARP, poly (ADP-ribose) polymerase; ICE, interleukin- $1 \beta$ converting enzyme; G3PDH, glyceraldehyde 3-phosphate dehydrogenase; 2D-PAGE, twodimensional polycrylamide gel electrophoresis

\section{Introduction}

Several lines of evidence implicate the involvement of the ubiquitin system in selective degradation and posttransla- tional processing of functionally important proteins, including transcription factors, oncoproteins and cyclins (reviewed in: Goldberg, 1992; Ciechanover, 1994; Hochstrasser, 1996). In addition to the regulation of physiological protein turnover, ubiquitination appears to represent one of the major biochemical pathways involved in mechanisms of cellular pathology. The increase in the expression of the polyubiquitin genes and ubiquitin protein levels has been identified in human neurodegenerative disorders, including Alzheimer's disease, Parkinson's disease, diffuse Lewy body disease and amyotrophic lateral sclerosis (reviewed in: Mayer et al, 1991). Furthermore, recent studies indicate that ubiquitin plays a major role in the posttranslational modification and removal of proteins during physiological programmed cell death. For instance, the programmed neuromuscular cell death in hawkmoth, Manduca sexta, is accompanied by an increase of polyubiquitin gene expression (Schwartz et al, 1990). Ubiquitin levels were also increased at certain stages of development in dying muscles and neurons in Drosophila, neurons of Manduca, tunicate stomach, and interdigital cells of chicken embryos (reviewed in: Schwartz et al, 1993). These data suggest that a common molecular response occurs in dying cells which involves the ubiquitin system.

Cell-damaging agents, such as hyperthermia, ionizing radiation and chemotherapeutic drugs activate expression of polyubiquitin genes (Fornace et al, 1989; Delic et al, 1993), suggesting a role for the ubiquitin pathway in experimentally-induced apoptosis. Indeed, recent studies have demonstrated that the immunoreactivity of ubiquitin was increased in human peripheral blood lymphocytes (Delic et al, 1993) and Ewing's sarcoma cells (Soldatenkov and Dritschilo, 1997) undergoing radiation-induced apoptosis. Here we have investigated whether a potential relationship exists between protein ubiquitination and apoptotic cell death triggered by factors other than ionizing radiation, and whether apoptotic cells exhibit different profiles of ubiquitinated proteins. We report that sodium butyrate induces apoptosis in MCF-7 breast carcinoma cells, and that apoptotic cells exhibit altered patterns of protein ubiquitination. These results indicate that the ubiquitin pathway may play a role in experimentallyinduced apoptosis.

\section{Results}

\section{Sodium butyrate induces apoptosis in MCF-7 cells}

Subconfluent cultures of logarithmically growing MCF-7 cells were treated with $3 \mathrm{mM}$ sodium butyrate, a fatty acid salt that is known to inhibit cell proliferation and induce apoptosis in many tumor cell types at concentrations of $2-5 \mathrm{mM}$ (Filippovich et al, 1988; Hague et al, 1993; Mandal and Kumar, 1996). We examined the kinetics of sodium butyrateinduced cell death by two-colour fluorescence cell viability 
assay based on simultaneous visualisation of viable and dead cells with two fluorogenic probes, calcein-AM and ethidium homodimer-1. In viable cells nonfluorescent calcein-AM is converted by intracellular esterases to the intensively fluorescent (green) calcein. In contrast, ethidium homodimer is excluded by viable cells but enters cells that have lost membrane integrity. Upon binding to nucleic acids, the ethidium homodimer produces bright red fluorescence. Thus, viable cells exhibit green fluorescence, dead cells appear red, and interference of red and green colors results in yellow fluorescence in dying cells (Han et al, 1997). As shown in Figure 1, exposure of MCF-7 cells to sodium butyrate resulted in a pronounced and time-dependent decrease in cell viability. By $48 \mathrm{~h}$ of incubation, significant number of cells started rounding-up and were shed into the culture medium. The decrease in numbers of viable cells (green) was coupled with the appearance of dead cells (red) and accumulation of detached (floating) cells in medium. Most of the floating cells (about $80 \%$ ) were permeable to ethidium homodimer and stained red, indicating ongoing cell death. In contrast, approximately $95 \%$ of the cells remaining attached were still viable as demonstrated by fluorescence activation of calceinAM.

To test whether MCF-7 cells undergo apoptosis following exposure to sodium butyrate, DNA fragmentation analysis was carried out in both adherent and floating cells (Figure 2A). DNA isolated from floating cells demonstrated a ladder-like pattern characteristic of inter-nucleosomal fragmentation, a biochemical marker of apoptosis (Wyllie et al, 1980), whereas adherent cells retained high molecular weight DNA. Recently, proteases of the ICE/ CED-3 family have been implicated in apoptosis induced by a variety of stimuli (reviewed in: Kumar, 1995). To determine whether sodium butyrate is capable of triggering the apoptosis-specific activation of the ICE/CED-3 proteolytic pathway, we examined the extent of PARP cleavage in
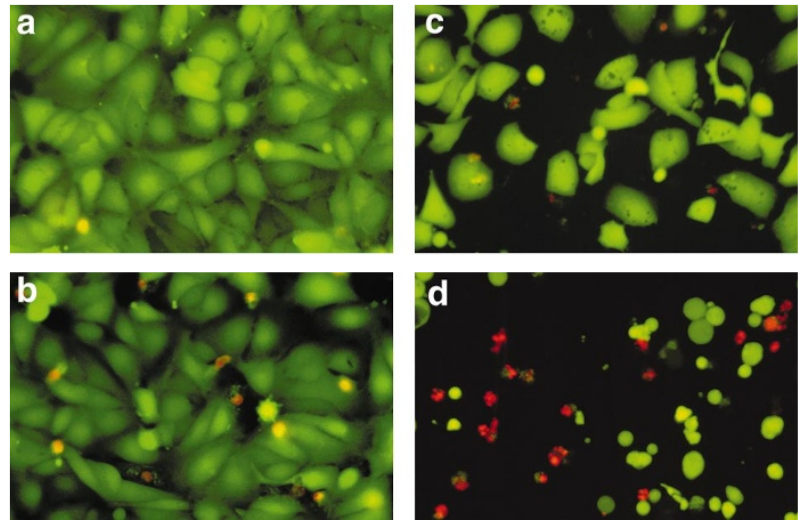

Figure 1 Effect of sodium butyrate on MCF-7 human breast carcinoma cells: induction of cell death. Cells were treated with $3 \mathrm{mM}$ sodium butyrate for $0 \mathrm{~h}$ (a), $24 \mathrm{~h} \mathrm{(b)} \mathrm{and} 48 \mathrm{~h} \mathrm{(c,} \mathrm{d).} \mathrm{Floating} \mathrm{cells} \mathrm{(d)} \mathrm{and} \mathrm{cells} \mathrm{remaining} \mathrm{attached} \mathrm{to}$ substrate $(\mathbf{a}, \mathbf{b}, \mathbf{c})$ were processed independently and stained with $2 \mu \mathrm{M}$ calcein-AM and $4 \mu \mathrm{M}$ ethidium homodimer-1 as described in Materials and Methods. Viable cells (green), dying cells (yellow), and dead cells (red) were detected by two-colour fluorescence cell viability assay and photographed under a Zeiss fluorescence microscope with exitation at $495 \mathrm{~nm}$. Representative fields are shown
MCF-7 cells. Consistent with the results of cell viability assays and DNA fragmentation analyses we observed the cleavage of $116 \mathrm{kDa}$ PARP protein to yield a characteristic $85 \mathrm{kDa}$ fragment of PARP in a population of floating cells (Figure 2B). Control (untreated) MCF-7 cells and cells remaining attached following exposure to sodium butyrate did not show evidence of apoptosis-specific proteolysis of PARP. These findings are in agreement with the reported capability of sodium butyrate to activate apoptotic pathways in mammalian cells (Filippovich et al, 1988; Hague et al, 1993; Mandal and Kumar, 1996), and provide the first evidence of the role for the ICE/CED-3 family of cysteine proteases in sodium butyrate-induced apoptosis of breast carcinoma cells.

\section{Sodium butyrate-induced apoptosis is accompanied by alterations in protein ubiquitination}

To investigate whether induction of apoptosis was accompanied by changes in protein ubiquitination we examined patterns of ubiquitin immunofluorescence and nuclear morphology in MCF-7 cells. As shown in Figure 3, a heterogeneous pattern of ubiquitin immunofluorescence was

a

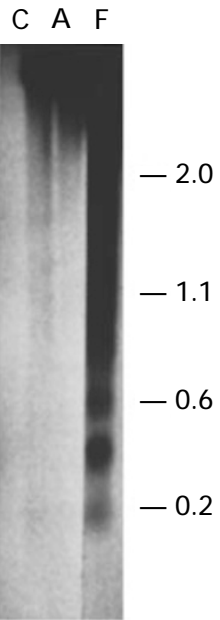

b

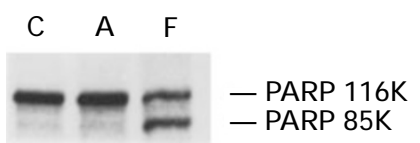

Figure 2 Sodium butyrate induces apoptosis in MCF-7 cells. Cells were treated with $3 \mathrm{mM}$ sodium butyrate for $48 \mathrm{~h}$. Floating $(\mathrm{F})$ and adherent $(A)$ cells were collected separately for subsequent analyses. Control, untreated cultures (C) contained less than $3 \%$ of floating cells and were analyzed in bulk. (A) Agarose gel electrophoresis of DNA. A typical 'ladder' pattern indicates internucleosomal DNA fragmentation in floating cells. The migration of molecular size markers (in kilobase pairs) is indicated on the right. (B) Immunodetection of PARP. Whole cell lysates were prepared from MCF-7 cells treated as indicated above. Cell samples containing equal amounts of protein $(25 \mu \mathrm{g})$ were electrophoresed and subjected to immunoblotting with the anti-PARP polyclonal antibody. The positions of native PARP $(116 \mathrm{kDa})$ and the proteolytic cleavage product of PARP $(85 \mathrm{kDa})$ are shown 
attributed to cells which had a normal nuclear morphology. In contrast, cells which revealed condensed nuclei, consistent with the morphology of apoptosis (Wyllie et al, 1980), also exhibited intense ubiquitin immunofluorescence. No significant alterations in antiubiquitin fluorescence intensity were detected prior to appearance of apoptosis-specific changes in nuclear morphology. These data indicate that apoptotic MCF7 cells accumulate ubiquitin and/or ubiquitinated proteins. Increased levels of ubiquitin-protein conjugates were also observed in peripheral blood lymphocytes (Delic et al, 1993) and Ewing's sarcoma cells (Soldatenkov and Dritschilo, 1997) undergoing radiation-induced apoptosis, in lethally heated HeLa cells (Carlson et al, 1987) and during developmentally programmed cell death (reviewed in: Schwartz et al, 1993). Thus, accumulation of ubiquitin appears to be a common feature of cells dying by apoptosis.

\section{Immunoblot analysis of ubiquitin conjugates in apoptotic MCF-7 cells}

We next examined the extent of ubiquitin incorporation into protein conjugates in sodium butyrate treated cells. In consideration of the results reported above (Figures 1 and 2) separate analyses were carried out in adherent and detached cells. Ubiquitin is known to be present in free form $\left(M_{r} 8000\right)$ and in association with various cellular proteins producing the conjugates with significantly higher molecular weights (Bush, 1984). Immunoblot analysis of MCF-7 cell extracts demonstrated the typical pattern of ubiquitinimmunoreactive bands that formed slow migrating ubiquitinconjugated proteins. Following treatment with sodium butyrate, cells remaining attached did not show significant

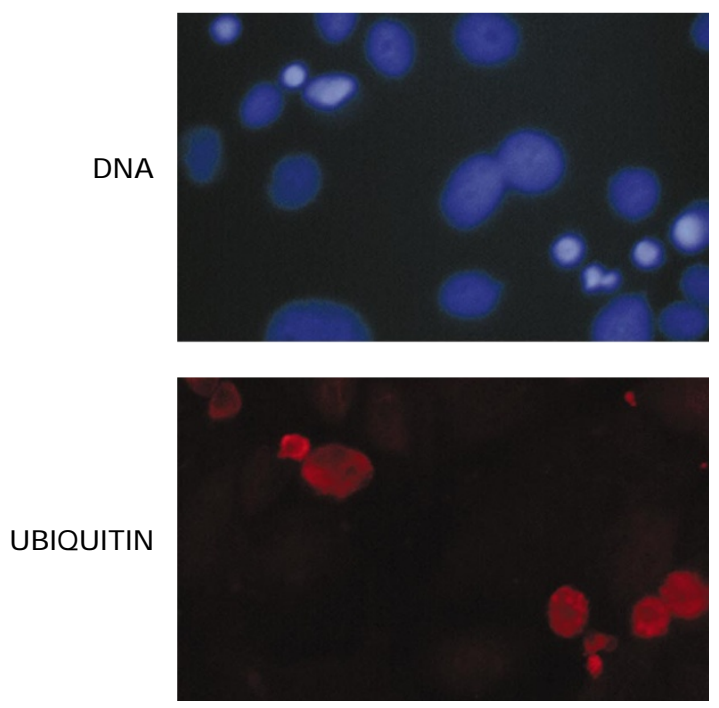

Figure 3 Increased ubiquitin immunostaining is associated specifically with apoptotic cells. Nuclear chromatin condensation and ubiquitin immunostaining in MCF-7 cells were examined following $48 \mathrm{~h}$ of treatment with sodium butyrate $(3 \mathrm{mM})$. Double staining of ubiquitin and DNA in MCF-7 cells were performed using anti-ubiquitin antibodies and DAPI as described in Material and Methods. The same fields were photographed at $\times 400$ magnification under a Zeiss fluorescent microscope to visualize DAPI-stained nuclear DNA and immunofluorescence of ubiquitin. A representative experiment (of three) is shown changes in the patterns of ubiquitinated proteins compared to control, untreated cells. In contrast, floating cells exhibited overall enhanced intensity of ubiquitin-immunoreactive bands, suggesting increased protein ubiquitination in apoptotic cells (Figure 4). Moreover, several ubiquitin-protein conjugates at $\mathrm{M}_{\mathrm{r}}$ approximately of $30 \mathrm{kDa}$ were accumulated specifically in floating cells. These data are consistent with the analyses of ubiquitin immunofluorescence in cells displaying an apoptosis-specific nuclear morphology (Figure 3), further strengthening the interpretation that alterations in protein ubiquitination occur specifically in apoptotic cells.

To further resolve the complex of ubiquitinated protein substrates, we employed two-dimensional gel electrophoresis following by immunoblot identification of ubiquitinprotein conjugates in attached and floating MCF-7 cells (Figure 5). The immunoreactive proteins are all concentrated in two groups, both in the acidic region at pl 4.2-4.6. Group I proteins resolve at an $M_{r}$ range of $70-90 \mathrm{kDa}$ while members of group II are located at an approximate $M_{r}$ of $30 \mathrm{kDa}$. It is of interest that the group I protein acceptors of ubiquitin are present in both attached and floating cells, while the ubiquitin-protein conjugates of group II are detectable only in floating cells. The appearance of the additional set of $3-4$ isomeric ubiquinated proteins in

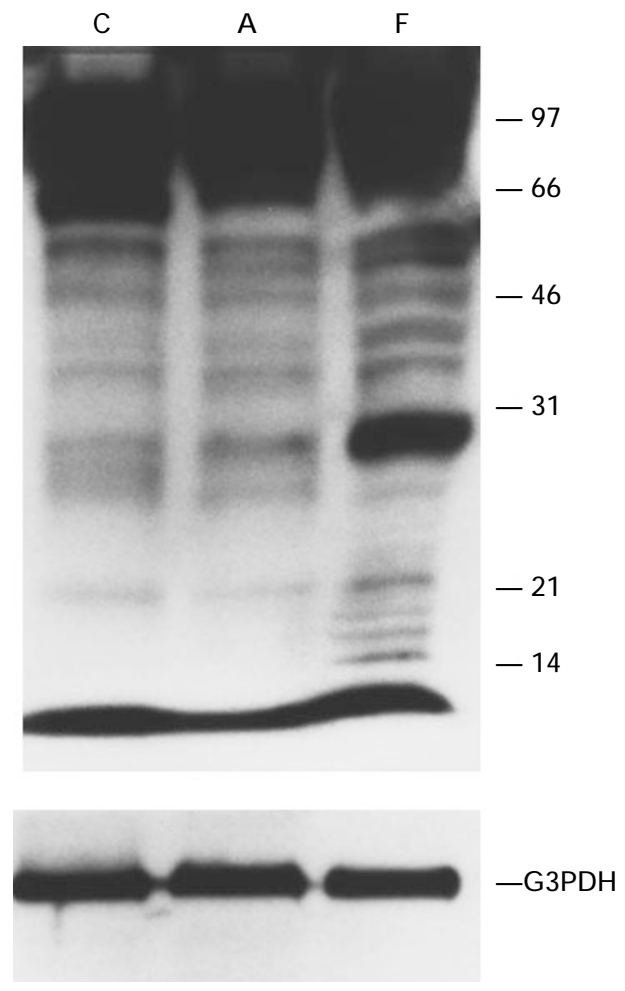

Figure 4 Detection of ubiquitin-immunoreactive proteins in MCF-7 cells exposed to sodium butyrate $(3 \mathrm{mM})$ for $48 \mathrm{~h}$. Floating $(F)$ and adherent $(A)$ cells were collected separately for analysis, and control cells $(C)$ were analyzed in bulk. Total cellular proteins $(25 \mu \mathrm{g})$ were resolved by SDS-PAGE $(4-20 \%$ gradient gel), transferred to Immobilon-P membranes, and immunoblotted with the monoclonal anti-ubiquitin antibody (top panel). The migration of appropriate molecular size markers (in kilodaltons) is indicated on the right. Immunodetection of the G3PDH is shown as a reference for protein loading equivalence (bottom panel) 
a

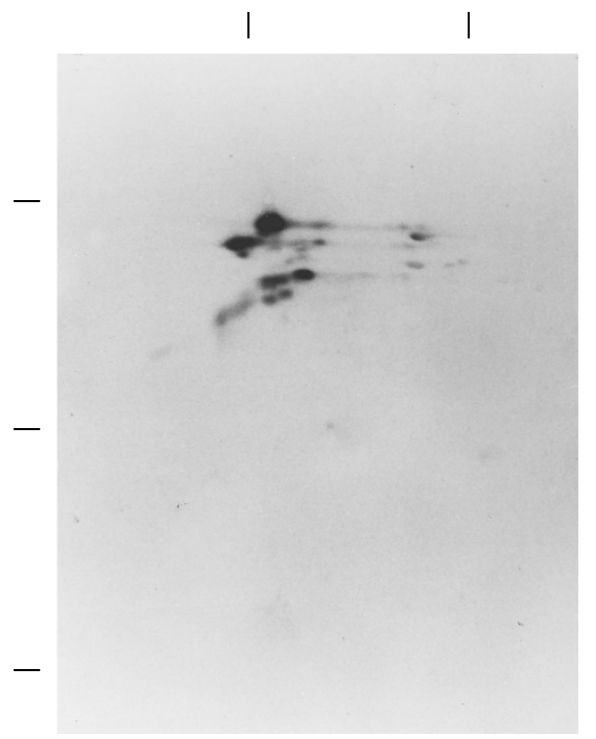

b

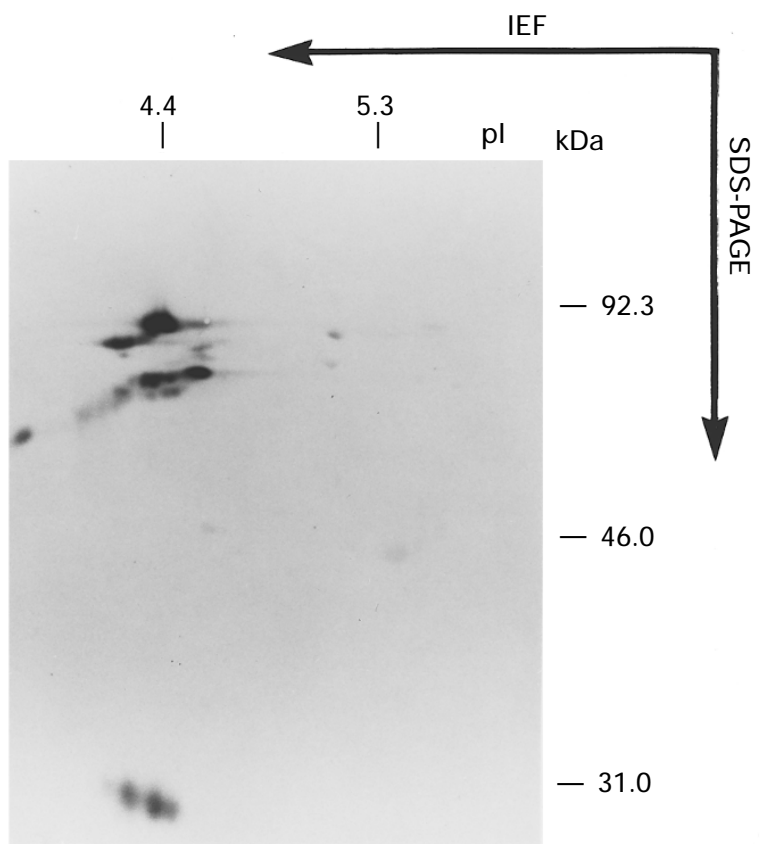

Figure 5 Two-dimensional immunoblot analysis of ubiquitin-conjugated proteins in MCF-7 cells. Following treatment with $3 \mathrm{mM}$ sodium butyrate for $48 \mathrm{~h}$ adherent (A) and floating (B) cells were collected separately for two-dimensional electrophoretic analysis. Immunoblot identification of ubiquitinated proteins was performed using the monoclonal anti-ubiquitin antibody (Chemicon). The immunoreactive proteins are all concentrated in two groups, both in the acidic region at a pl $4.2-4.6$. Group I protein acceptors resolve at an $\mathrm{M}_{\mathrm{r}}$ range of $70-90 \mathrm{kDa}$ while group II proteins are located at an $\mathrm{M}_{\mathrm{r}}$ approximately of $30 \mathrm{kDa}$. The protein loading was equivalent in the gels used for immunoblotting as judged by comparable coomassie stain prior to using the membranes for subsequent immunodetection of ubiquitin

floating cell population indicates the specificity of these conjugates to apoptotic cells. At present it is unknown whether these protein isoforms represent intermediates in the ubiquitin-mediated proteolysis of protein targets or correspond to novel ubiquitinated products in the apoptotic pathway. Ubiquitin is a basic protein, and ubiquitination renders the protein acceptors to be more basic (Bush, 1984). Therefore, the acidic nature of these proteins suggests that in addition to ubiquitination they might have also undergone additional posttranslational modifications such as phosphorylation or glycosylation, or both. Recently the mechanistic link between site-specific phosphorylation of proteins and ubiquitination has been demonstrated (Chen et al, 1995). The identity of ubiquitin-immunoreactive proteins in apoptotic MCF-7 cells and any precursor product relationship between them are currently under investigation.

\section{Discussion}

We report here that sodium butyrate-induced apoptosis is associated with increased ubiquitin immunoreactivity in MCF7 cells. Accumulation of ubiquitin-protein conjugates was observed specifically in cells which exhibited apoptotic morphology and biochemical criteria of apoptosis pointing to a possible relationship between function(s) of the ubiquitin pathway and the apoptotic process. In living cells, ubiquitinated proteins are rapidly degraded by the $26 \mathrm{~S}$ proteasome, a complex with multiple proteinase activity (reviewed in:
Goldberg, 1992; Ciechanover, 1994). Therefore, accumulation of ubiquitin-protein conjugates in dying cells may reflect the disturbed equilibrium between protein ubiquitination and proteasome-dependent degradation.

Although the mechanisms leading to the observed alterations remain to be investigated, several explanations can be considered. First, protein ubiquitination appears to have been adapted as part of an intracellular surveillance system that can be activated by altered or foreign proteins (Carlson et al, 1987; Fornace et al, 1989; Mayer et al, 1991). Accordingly, the accumulation of ubiquitinated proteins may reflect the activation of the ubiquitin pathway as a part of the cytoprotective mechanism in chronically stressed and/or damaged cells. Second, abnormal function of the proteasome may also result in accumulation of ubiquitinated proteins in apoptotic cells. This interpretation is supported by our findings that inhibition of proteasome function in human tumor cells resulted in accumulation of ubiquitin-protein conjugates in a dose dependent fashion and activated apoptotic pathways in Ewing's sarcoma cells (Soldatenkov and Dritschilo, 1997). The role of the proteasome in the apoptotic process has also been demonstrated in other in vitro studies (Imajoh-Ohmi et al, 1995; Grimm et al, 1996; Saoul et al, 1996; Drexler, 1997). Moreover, structural and functional changes in the 26S proteasome occur during developmentally programmed cell death in muscles of Manduca sexta (Jones et al, 1995; Low et al, 1997). Third, the selective accumulation of ubiquitinprotein conjugates may be accounted for by increased 
resistance of ubiquitinated proteins to proteolysis. Escape of ubiquitinated proteins from degradation is not unique since stable conjugates are found with histones (Wu et al, 1981), actin (Ball et al, 1987) and cell surface proteins (Siegelman et al, 1986). Moreover, accumulation of high molecular weight ubiquitin-protein conjugates was found to be coupled with acquired stabilization of ubiquitinated endogenenous and injected proteins in heat-shocked HeLa cells (Carlson et al, 1987).

Recent studies have demonstrated that the ubiquitin pathway is involved in the regulation of basal or stimuliinduced turnover of oncoproteins and transcriptional regulators ( $\mathrm{p} 53, \mathrm{c}-\mathrm{fos}, \mathrm{c}-j u n$, and $\mathrm{NF}-\kappa \mathrm{B}$ ), cell surface receptors, cyclins (reviewed in: Ciechanover, 1994) and the cyclin-dependent kinase inhibitor p27 ${ }^{\mathrm{Kip} 1}$ (Pagano et al, 1995). Accordingly, ubiquitin-mediated changes in the stability of functionally important proteins may play an essential role in apoptotic pathways. Further investigations are necessary to understand the mechanisms underlying stabilization of ubiquitinated proteins, to identify the apoptosis-specific protein targets for ubiquitin and resolve the questions of ubiquitinated protein targets in apoptosis. The latter may lead to the identification of critical intracellular mediators of apoptosis.

\section{Materials and Methods}

\section{Cell culture and apoptosis induction}

Human breast carcinoma MCF-7 cells were cultured in IMEM medium (Biofluids, Inc.) supplemented with $10 \%$ heat inactivated fetal bovine serum, $2 \mathrm{mM}$ glutamine, 100 units $/ \mathrm{ml}$ penicillin and $100 \mu \mathrm{g} / \mathrm{ml}$ streptomycin. Cells were maintained as monolayers at $37^{\circ} \mathrm{C}$ in an atmosphere of $5 \% \mathrm{CO}_{2}$. Exponentially growing cells were treated with sodium butyrate (Calbiochem) dissolved in medium to the indicated final concentration.

\section{Two-color fluorescence cell viability assay}

Cells were grown on sterile 18-mm glass coverslips (Fisher) placed in 35-mm wells of a six-well culture dish (Costar). Following treatment with $3 \mathrm{mM}$ sodium butyrate, medium was removed and detached (floating) cells were collected by centrifugation. Floating cells and cells remaining attached to substrate were processed simultaneously according to manufacturer's protocol. Briefly, cells were washed with phosphatebuffered saline (PBS) and stained with $2 \mu \mathrm{M}$ calcein-AM and $4 \mu \mathrm{M}$ ethidium homodimer (LIVE/DEAD Viability/Cytotoxicity Assay Kit; Molecular Probes, Inc.) for $35 \mathrm{~min}$. Labelled cells were immediately viewed and photographed under a Zeiss (Axiovert 135, Carl Zeiss Inc., Germany) fluorescence microscope with exitation at $495 \mathrm{~nm}$.

\section{Immunofluorescence staining and microscopy}

For simultaneous staining of DNA and ubiquitin, MCF-7 cells were grown on glass coverslips placed in $35-\mathrm{mm}$ wells of a six-well culture dish. Following treatment with $3 \mathrm{mM}$ sodium butyrate, floating cells were spun down on coverslips and medium was carefully removed. Cells were rinsed twice with PBS, fixed in PBS - $3.7 \%$ paraformaldehyde for $10 \mathrm{~min}$, washed three times in PBS for $5 \mathrm{~min}$ each, and then were permeabilized with PBS- $0.2 \%$ Triton X-100 for $10 \mathrm{~min}$. After three washes with PBS cells were incubated for $30 \mathrm{~min}$ with anti-ubiquitin antibodies (1:100, Chemicon). Washes were followed by incubation with affinity purified Texas Red-conjugated donkey anti-rabbit IgG antibody (1:300, Jackson ImmunoResearch) and DAPI solution $(0.5 \mu \mathrm{g} / \mathrm{ml}$, Sigma $)$ for $30 \mathrm{~min}$ in the dark Coverslips were then washed with PBS, blotted dry and mounted onto glass slides using a Prolong Antifade Kit (Molecular Probes, Inc.). Epifluorescence microscopy was performed using a Zeiss Photoscope II (Carl Zeiss, Inc.) equipped with a Zeiss Plan $40 \times / 0.65$ NA objective, and cells were photographed using a $35 \mathrm{~mm}$ camera. Specificity of ubiquitin immunofluorescence was confirmed by the absence of Texas-Red cell staining when the primary antibody was omitted. The apoptotic cells were underrepresented in these experiments due to the loss of floating cells following washes.

\section{Analysis for apoptosis}

For quantitation of apoptosis, adherent and floating cells were pooled together and washed with PBS prior to fixation with $3.7 \%$ paraformaldehyde for 3-5 min. After rehydration in PBS, cells were stained with DAPI for 30 min in the dark, mounted with coverslips and visualized by fluorescence microscopy using a Zeiss Photoscope II. The apoptotic cells exhibiting condensed and fragmented nuclei were readily visible and scored positive. Using a $\times 40$ objective lens, apoptotic nuclei were counted in five to seven randomly selected fields. A minimum of 400-500 nuclei was examined for each case, and the results were expressed as the number of apoptotic nuclei over the total number of nuclei counted.

\section{DNA fragmentation assays}

For analysis of oligonucleosomal DNA fragmentation, total cellular DNA was prepared as described previously (Soldatenkov et al, 1995). Briefly, harvested cells were washed in PBS and resuspended in lysis buffer (10 mM Tris $\mathrm{HCl}$, pH 8.0-5 mM EDTA-1\% SDS $-50 \mu \mathrm{g} / \mathrm{ml}$ RNase A) followed by incubation for $1 \mathrm{~h}$ at $37^{\circ} \mathrm{C}$. Cell lysates were treated with proteinase $\mathrm{K}(100 \mu \mathrm{g} / \mathrm{ml})$ in the presence of $1 \mathrm{M} \mathrm{NaCl}$ for $3 \mathrm{~h}$ at $37^{\circ} \mathrm{C}$. DNA was extracted with phenol:chloroform:isoamyl alcohol, precipitated with ethanol, recovered by centrifugation and resuspended in TE - buffer (10 mM Tris $\mathrm{HCl}$, pH 7.5-1 mM EDTA). Recovered DNA samples were applied to $2 \%$ agarose gels and electrophoresed for $16 \mathrm{~h}$ at $1.5 \mathrm{~V} / \mathrm{cm}$.

\section{D-PAGE}

Iso-Dalt equipment from Hoefer Scientific was utilized. Procedures were carried out essentially as described by O'Farrel (1975) with minor modifications to suit Iso-Dalt equipment. Isoelectric focussing gel tubes were made up of $3-5 \%$ acrylamide, $9 \mathrm{M}$ urea, $2 \%$ ampholines $(1: 3$ of $\mathrm{pH} 3.5-10.0$ and $\mathrm{pH} 4.0-8.0), 2 \%$ nonidet -40 (NP-40), $0.03 \%$ ammonium persulfate, and $0.01 \%$ TEMED ( $\mathrm{N}, \mathrm{N}, \mathrm{N}^{\prime} \mathrm{N}^{\prime}$-tetramethylene diamine). Total cell lysates were prepared in iso-sample buffer $\left(5 \times 10^{6}\right.$ cells in $\left.250 \mu \mathrm{l}\right)$ made up of $9 \mathrm{M}$ urea, $4 \%$ NP-40, 2\% ampholines (pH 8-10), and 1\% dithiothreitol. 15$20 \mu \mathrm{l}$ of whole cell lysates were subjected to 2D-PAGE. Proteins were focussed for approximately $24000 \mathrm{~V} \mathrm{~h}$ (first dimension) and the isotubes transferred to $10 \%$ polyacrylamide slab gels for electrophoresis (second dimension) overnight at $100 \mathrm{~V}$ at $20^{\circ} \mathrm{C}$. The gels were transblotted for subsequent immunoblotting in a semidry blotter (Hoefer Scientific Instruments) with a buffer of $25 \mathrm{mM}$ Tris - $192 \mathrm{mM}$ Glycine-20\% methanol, pH 8.3. 


\section{Western immunoblot analyses}

Cells were washed twice with cold PBS and lysed at $4{ }^{\circ} \mathrm{C}$ for $30 \mathrm{~min}$ in buffer: $1 \%$ Triton X-100, $0.1 \%$ SDS, $0.5 \%$ sodium deoxycholate, $100 \mathrm{mM} \mathrm{NaCl}, 1 \mathrm{mM}$ phenylmethylsulfonyl fluoride, $20 \mu \mathrm{g} / \mathrm{ml}$ aprotinin, $20 \mu \mathrm{g} / \mathrm{ml}$ leupeptin. Insoluble material was removed by centrifugation at $4^{\circ} \mathrm{C}$ for $30 \mathrm{~min}$ at $16000 \times \mathrm{g}$ and protein concentration was determined using the Micro BCA protein assay (Pierce). Cellular proteins $(25-30 \mu \mathrm{g} / \mathrm{sample})$ were resolved by SDS-PAGE (4-20\% gradient gel, BioRad), and transferred to Immobilon-P membranes (Millipore) followed by blocking with $5 \%$ BSA, incubation with primary antibody and detection of specific proteins by the enhanced chemiluminescence method according to the manufacturer's protocol (Amersham). Assessment of apoptosisrelated proteolytic cleavage of poly(ADP-ribose) polymerase was performed as previously described (Soldatenkov et al, 1995) using a rabbit polyclonal antibody against the full length PARP $(1: 2000$, Boehringer). For immunodetection of ubiquitinated proteins the cellular extracts were prepared in the presence of $0.1 \%$ SDS and $5 \mathrm{mM} \mathrm{N}$ ethylmaleimide to inhibit potent isopeptidase activities that may affect the detection of multi-ubiquitinated proteins (Kim and Maniatis, 1996). The membrane-bound proteins were subjected to immunoblotting with monoclonal antisera to ubiquitin (Chemicon) at a dilution of $1: 1000$. Equal sample loading was confirmed by reprobing the same blots with a rabbit polyclonal antiserum against glyceraldehyde 3-phosphate dehydrogenase, G3PDH (1:5000, Trevigen).

\section{Acknowledgements}

This work was supported in part by Grants \# CA 45408 and CA 74175 from the National Institute of Health (to A.D.) and a Research Starter Grant Award from Georgetown University Medical Center (to V.A.S.). We thank Dr. A. Mukhin for help with image analyses. Fluorescent microscopy and 2D-gel protein separation were performed using the Microscopy/lmaging and 2D-Gel Electrophoresis Shared Resources of the Lombardi Cancer Center, Georgetown University, Washington, D.C. (USPHS Grant 2P30-CA-51008).

\section{References}

Ball E, Karlik CC, Beal CJ, Saville DL, Sparrow JC, Bullard B and Fyrberg EA (1987) Arthrin, a myofibrillar protein of insect flight muscle, is an actin-ubiquitin conjugate. Cell 51: 221-228

Bush H (1984) Ubiquitination of proteins. Methods Enzymol. 106: 238-262

Carlson N, Rogers Sand Rechsteiner M(1987) Microinjection of ubiquitin: changes in protein degradation in HeLa cell subjected to heat-shock. J. Cell. Biol. 104:547555

Chen Z, Hagler J, Palombella VJ, Melandri F, Scherer D, Ballard D and Maniatis T (1995) Signal-induced site-specific phosphorylation targets $\mathrm{l}_{\kappa} \mathrm{B} \alpha$ to the ubiquitinproteasome pathway. Genes and Dev. 9: 1586-1597

Ciechanover A (1994) The ubiquitin-mediated proteolytic pathway: mechanisms of action and cellular physiology. Biol.Chem. Hoppe-Seyler 375: 565-581

Delic J, Morange M and Magdelenat H (1993) Ubiquitin pathway involvement in human lymphocyte $\gamma$-irradiation-induced apoptosis. Molec. Cell. Biol. 13:48754883

Drexler HCA (1997) Activation of the cell death program by inhibition of proteasome function. Proc. Natl. Acad. Sci. USA 94: 855-860

Filippovich IV, Sorokina NI, Soldatenkov VA, Alfyerova TM and Trebenok ZA (1988) Effect of the inducers of cellular differentiation and ionizing radiation on thymus lymphocytes: chromatin degradation and programmed cell death. Int. J. Radiat. Biol. 53: $617-628$
Fornace AJ, Alamo I, Hollander MC and Lamoreaux E (1989) Ubiquitin mRNA is a major stress-induced transcript in mammalian cells. Nucl. Acids Res. 17: 12151230

Goldberg AL (1992) The mechanism and functions of ATP-dependent proteases in bacterial and animal cells. Eur. J. Biochem. 203: 9-23

Grimm LM, Goldberg AL, Poirier GG, Schwartz LM and Osborne B (1996) Proteasomes play an essential role in thymocyte apoptosis. EMBO J. 15: $3835-$ 3844

Hague A, Manning AM, Hanlon KA, Huschtscha LI, Hart D and Paraskeva C (1993) Sodium butyrate induces apoptosis in human colonic tumor cell lines in a p53independent pathway: implications for the possible role of dietary fibre in the prevention of large-bowel cancer. Int. J. Cancer 55: 498-505

Han J, Dionne CA, Kedersha NL and Goldmacher VS (1997) p53 status affects the rate of the onset but not the overall extent of doxorubicin-induced cell death in Rat-1 fibroblasts constitutively expressing c-Myc. Cancer Res. 57: 176-182

Hochstrasser M (1996) Protein degradation or regulation: Ub the judge. Cell 84 : 813-815

Imajoh-Ohmi S, Kawaguchi T, Sugiyama S, Tanaka K, Omura S and Kikuchi H(1995) Lactacystin, a specific inhibitor of the proteasome, induces apoptosis in human monoblast U937 cells. Biochem. Biophys. Res. Commun. 217: 1070-1077

Jones ME, Haire M, Kloetzel P, Mykles D and Schwartz LM (1995) Changes in the structure and fuction of the multicatalytic proteinase (proteasome) during programmed cell death in the intersegmental muscles of the hawkmoth, Maduca sexta. Dev. Biol. 169: 436-447

Kim TK and Maniatis T (1996) Regulation of interferon- $\gamma$-activated STAT1 by the ubiquitin-proteasome pathway. Science 273: 1717-1719

Kumar S (1995) ICE-like proteases in apoptosis. Trends Biochem. Sci. 20: 198-202

Low P, Bussel K, Dawson SP, Billett MA, Mayer RJ and Reynolds SE (1997) Expression of a $26 \mathrm{~S}$ proteasome ATPase subunit, MS73, in muscles that undergo developmentally programmed cell death, and its control by ecdysteroid hormones in the insect Manduca sexta. FEBS Lett. 400: 345-349

Mandal M and Kumar R (1996) Bcl-2 expression regulates sodium butyrate-induced apoptosis in human MCF-7 breast cancer cells. Cell Growth Differ. 7: 311-318

Maki CG, Huibregtse JM and Howley PM (1996) In vivo ubiquitination and proteasome-mediated degradation of p53. Cancer Res. 56: 2649-2654

Mayer JR, Arnold J, Laszlo L, Landon M and Lowe J (1991) Ubiquitin in health and disease Biochim. Biophys. Acta 1089: 141-157

O'Farrel PH (1975) High resolution two-dimensional electrophoresis of proteins. J. Biol. Chem. 250: 4007-4021

Pagano M, Tam SW, Theodoras AM, Beer-Romero P, Del Sal G, Chau V, Yew PR, Draetta GF and Rolfe M (1995) Role of the ubiquitin-proteasome pathway in regulating abundance of the cyclin-dependent kinase inhibitor p27. Science 269: $682-685$

Saoul R, Fernandez PA, Quiquerez AL, Martinou I, Maki M, Schroter M, Becherer JD, Irmler M, Tschopp Jand Martinou JC (1996) Involvement of the proteasome in the programmed cell death of NGF-deprived sympathetic neurons. EMBO J. 15: $3845-3852$

Schwartz LM, Kosz L and Kay BK (1990) Gene activation is required for developmentally programmed cell death. Proc. Natl. Acad. Sci. USA 87: $6594-6598$

Schwartz LM, Smith SW, Jones MEE and Osborne BA (1993) Do all programmed cell death occur via apoptosis? Proc. Natl. Acad. Sci. USA 90: 980-984

Siegelman M, Bond MW, Gallatin WM, John TS, Smith HT, Fried VA and Weissman IL (1986) Cell surface molecule associated with lymphocyte homing is a ubiquitinated branched-chain glycoprotein. Science 231: 823-829

Soldatenkov VA, Prasad S, Notario V and Dritschilo A (1995) Radiation-induced apoptosis of Ewing's sarcoma cells: DNA fragmentation and proteolysis of poly (ADP-ribose) polymerase. Cancer Res. 55: 4240-4242

Soldatenkov VA and Dritschilo A (1997) Apoptosis of Ewing's sarcoma cells is accompanied by accumulation of ubiquitinated proteins. Cancer Res. 57:3881 3885

Wu RS, Kohn KW and Bonner WM (1981) Metabolism of ubiquitinated histones. J. Biol. Chem. 256: 5916-5920

Wyllie AH, Kerr JFR and Currie AR (1980) Cell death: the significance of apoptosis. Int. Rev. Cytol. 68: 251-306 